\section{Guidelines for Physician- Assisted Suicide: Can the Challenge Be Met?}

\author{
Carl H. Coleman, Alan R. Fleischman
}

$\mathrm{T}$

he question of legalizing physician-assisted suicide (PAS) has become a serious public debate. Growing interest in assisted suicide reflects a public increasingly fearful of the process of dying, particularly the prospect of dying a painful, protracted, or undignified death. PAS has been proposed as a compassionate response to unrelievable suffering, designed to give terminally or incurably ill individuals direct control over the timing, manner, and circumstances of their death. Although the American Medical Association remains firmly opposed to legalizing PAS, ${ }^{1}$ many physicians have begun to express support for the practice, and some have acknowledged that they have helped patients commit suicide despite the existing legal ban. ${ }^{2}$

As support for PAS grows, it becomes increasingly likely that the practice will be legalized in at least some states in the not-too-distant future. In 1994, Oregon voters approved a referendum legalizing PAS for competent, terminally ill patients; ${ }^{3}$ a federal court injunction preventing the referendum from going into effect is currently on appeal, and it is widely expected that the injunction will be lifted. ${ }^{4}$ Proposals to legalize assisted suicide are also pending in at least a dozen state legislatures. ${ }^{5}$ More significant, two federal appellate courts recently concluded that absolute prohibitions on assisted suicide violate the constitutional rights of competent, terminally ill patients who wish to hasten death. ${ }^{6}$ If the United States Supreme Court affirms one or both of these decisions, absolute prohibitions against assisted suicide may no longer be enforceable in any state. Even if the Court reverses both decisions, states would remain free to legalize assisted suicide through legislation, referenda, or judicial interpretation of state constitutional guarantees.

Journal of Law, Medicine \& Ethics, 24 (1996): 217-24. (C) 1996 by the American Society of Law, Medicine \& Ethics.
Nonetheless, although a few supporters of PAS oppose any legal restrictions on the practice, most who advocate legalization believe that limitations of some sort are essential, to ensure that assisted suicide remains an option of last resort. ${ }^{7}$ Indeed, most proponents of legalization emphasize that laws discouraging suicide serve important societal interests, especially when applied to cases involving healthy individuals suffering from reversible physical or psychological problems. As Judge Stephen Reinhardt of the Ninth Circuit Court of Appeals observed before striking down Washington State's assisted suicide prohibition as applied to mentally competent, terminally ill patients, "the state has a clear interest in preventing anyone, no matter what age, from taking his own life in a fit of desperation, depression, or loneliness or as a result of any other problem, physical or psychological, which can be significantly ameliorated." In such cases, he wrote, "the heartache of suicide is the senseless loss of a life ended prematurely," and the state can legitimately take steps to prevent these suicides from taking place. ${ }^{8}$

\section{Proposed guidelines for PAS}

The growing support for PAS as ethically defensible for competent individuals experiencing unrelievable suffering caused by terminal or incurable illness has prompted several efforts to develop guidelines for implementing PAS, should the practice be legalized. The first set of such guidelines appeared in an article by Drs. Timothy Quill, Christine Cassel, and Diane Meier, published in the New England Journal of Medicine in 1992 (the Quill Guidelines). ${ }^{9}$ The proposed guidelines specify that the patient must suffer from an "incurable condition" associated with "severe, unrelenting suffering." The patient must repeatedly request suicide assistance, and consent to assisted suicide must be 
in writing. Physicians must ensure that the patient's judgment is not distorted by reversible depression and that all reasonable comfort measures have at least been considered, "and preferably have been tried." According to the guidelines, PAS would be limited to patients in a "meaningful doctor-patient relationship."

Two years after the Quill Guidelines were issued, a group of doctors, lawyers, and ethicists (including Drs. Quill and Meier) published a set of guidelines in the New England Journal of Medicine (the Miller Guidelines). ${ }^{10}$ A notable change from the Quill Guidelines was the Miller Guidelines' embrace of voluntary euthanasia (that is, physician-administered lethal injections) as an option for cognitively capacitated patients who are unable to commit suicide by self-administering lethal drugs. Although many proponents of PAS take pains to distinguish the practice from euthanasia, ${ }^{11}$ the authors of the Miller Guidelines reasoned that "to confine physician-assisted death to assisted suicide unfairly discriminates against patients with unrelievable suffering who resolve to end their lives but are physically unable to do so."12

The Miller Guidelines also differed from the Quill Guidelines by proposing an extensive method for prospective and retrospective review of the practice, instead of relying on the judgment of one or two physicians acting at the bedside. Under the Miller Guidelines, all patients who request assisted suicide would be referred to independent, certified palliative care consultants who would be required to examine the patient's medical records and to interview the treating physician, the patient, and interested members of the patient's family. The consultant's goal would be to determine "whether the treating physician and patient had considered carefully all reasonable alternatives" and to assess "the voluntariness of the patient's request to die and the strength of his or her resolve." The consultant could request additional expert advice, and could refer particularly difficult cases for prospective review to regional palliative care committees. If the consultant determined that assisted suicide was inappropriate, he/she would be required to prepare "a reasoned and clearly articulated statement" justifying this judgment, which the patient and physician could then appeal to the regional palliative care committee. In all cases, the consultant would be required to prepare a confidential written report that would be submitted to the palliative care committee for retrospective monitoring.

Perhaps not surprisingly, none of the pending state legislative proposals to legalize PAS has adopted the Miller Guidelines. Rather, most of the pending state bills follow the Quill Guidelines' emphasis on the attending and consulting physicians, who are given almost exclusive responsibility for evaluating the patient and determining whether to comply with the request. Many of the pending bills are modeled explicitly on Oregon's Death with Dignity Act (the Oregon Act), also known as Proposition $16 .{ }^{13}$ The
Oregon Act contains strict timetables (for example, the patient must make two oral requests and one written request; no less than fifteen days can elapse between the patient's initial oral request and the writing of a prescription; and no less than forty-eight hours can elapse between the patient's written request and the writing of a prescription), and specifies particular disclosures that every physician must make (for example, the physician must inform the patient that he/she has an opportunity to rescind the request at any time and must offer the patient an opportunity to rescind at the end of the fifteen-day waiting period). The Act also contains numerous documentation requirements and immunity provisions, and directs the state health department to monitor the practice and conduct retrospective review.

In 1996, a group of doctors, lawyers, and ethicists, none of whom had participated in the development of the Quill or Miller Guidelines, proposed model legislation to authorize and regulate PAS (the Model Act). ${ }^{14}$ Like the Quill Guidelines and most pending state legislative proposals, the Model Act relies on the patient's physician, in cooperation with other health care professionals, to screen out inappropriate cases and to ensure that all available alternatives are explored. Yet it goes beyond the Quill Guidelines and other proposals in several important respects. Most significant, the Model Act specifies that, in all cases, the physician must secure a written opinion from a licensed psychiatrist, clinical psychologist, or psychiatric social worker who has examined the patient and determined that the request is not the result of a distortion of the patient's judgment due to clinical depression or any other mental illness. The Model Act also requires the physician to discuss with the patient all available medical information in the presence of two adult witnesses, at least one of whom is not affiliated with any person involved in the care of the patient and does not stand to benefit personally in any way from the patient's death.

\section{Evaluating the guidelines}

Efforts to create guidelines for PAS reflect a well-intentioned desire to balance compassion for a relatively small group of individuals with unrelievable suffering and the need to protect vulnerable patients from mistake and abuse. We are greatly concerned, however, that the premise of the guidelines-the notion that assisted suicide, if legalized, can be limited to a specific class of ethically acceptable cases-will prove impossible to realize in everyday medical practice. It is therefore extremely important to evaluate the proposed guidelines in light of their logic, ethical soundness, and adherence to generally accepted legal and medical norms. To some, extending the availability of PAS beyond the categories now being debated is a desirable outcome of legalization, not a risk. ${ }^{15}$ Many more people, 
however, appear to believe that the limitations on assisted suicide contained in the pending proposals are critical safeguards against mistake and abuse. Indeed, it was only after advocates for legalization abandoned the concept of lethal injections in favor of prescriptions for lethal drugs that a ballot initiative to legalize the practice was able to garner the approval of voters in Oregon. ${ }^{16}$

We believe that guidelines are unlikely to limit assisted suicide to a narrowly defined set of circumstances, and for that reason we oppose legalization of PAS. Likewise, concern that limits on PAS would be unenforceable led the New York State Task Force on Life and the Law, a nonpartisan governmental advisory commission made up of physicians, nurses, lawyers, ethicists, and representatives of a variety of religious and civic organizations, to recommend unanimously that existing prohibitions on assisted suicide remain in place. ${ }^{17}$ Although many Task Force members believed that assisted suicide could be ethically defensible in exceptional cases, all members concluded that the practice, if legalized, could not effectively be limited to any narrowly defined set of circumstances. "The criteria and safeguards that have been proposed for assisted suicide and euthanasia," the Task Force observed, "would prove elastic in clinical practice and law." 18 Moreover, "[n]o matter how carefully any guidelines are framed, assisted suicide and euthanasia will be practiced through the prism of social inequality and bias that characterizes the delivery of services in all segments of our society, including health care. ${ }^{19}$ Echoing these concerns, Daniel Callahan and Margot White have suggested that efforts to develop PAS guidelines will produce nothing more than "an elaborate regulatory facade concealing a poverty of potential for actual enforcement." ${ }^{20}$ According to Callahan and White, "the nature of the doctor-patient relationship and of the medical procedures themselves renders them resistant to the standards asked for by one article: 'clear criteria, rigorous procedures, and adequate safeguards."' 21

The ability of the state and the medical profession to distinguish between appropriate and inappropriate cases of suicide assistance is at the heart of the current debate over the constitutionality of laws prohibiting assisted suicide in all cases. ${ }^{22}$ Even if some decisions to commit suicide implicate constitutionally protected liberty interests, absolute prohibitions on assisted suicide would remain constitutionally permissible if the state could show that allowing exceptions would lead to unacceptable levels of mistake and abuse. ${ }^{23}$ Apart from the constitutional issues, the ability of the state to set enforceable limits on assisted suicide should also concern legislators and policy makers as they consider assisted suicide as a matter of prudent public health policy.

In considering the likely effectiveness of guidelines, it is important to separate two distinct, although related, concerns. The first is the slippery slope problem-that as- sisted suicide, once legalized for terminally ill patients or other narrowly defined classes of individuals, will be used in a far broader set of circumstances. The second concern is that, even if criteria can be established for ethically defensible cases, many physicians-even those acting with the best of intentions - may not be able to determine validly and consistently whether those criteria have been met.

\section{Slippery slope concerns}

For those uncomfortable with the prospect of PAS and euthanasia becoming commonplace, concerns about the slippery slope are not idle debating points, but "expressions of caution in the face of unknown future changes." 24 Slippery slope arguments are widely overused; the risk that limits will not be respected is inherent in all new endeavors, and cannot automatically outweigh the interests of those who seek change. At the same time, some slopes are more slippery than others, and some risks are more dangerous to assume. Concerns about the slippery slope are particularly appropriate when the proposed lines are arbitrary and not subject to principled analysis, and when the consequences of slippage are severe and irremediable. Indeed, many supporters of PAS have been the first to raise slippery slope arguments in other contexts, such as cases challenging limitations on free speech, suggesting that they recognize the dangers that unstable limitations can pose. ${ }^{25}$

Three slippery slope arguments are of particular concern here. The first relates to the medical conditions proposed as criteria for eligibility. Although the Quill Guidelines, the Miller Guidelines, and the Model Act all reject terminal illness as a prerequisite for suicide assistance, the Oregon Act and most of the pending state legislative proposals to legalize assisted suicide explicitly limit the right to patients with six months or less to live. Likewise, the plaintiffs in the pending constitutional litigation have carefully limited their claim to terminally ill patients, enabling them to dismiss concerns about assisted suicide for other individuals who are suffering as irrelevant and outside the scope of the litigation. ${ }^{26}$ Some have even argued that a terminally ill patient who self-administers lethal drugs is not committing suicide, but simply "hastening inevitable death," a decision described as qualitatively different from that of a nonterminally ill individual to take his/her life. ${ }^{27}$

Although the focus on assisted suicide for patients already close to death makes sense as a public relations strategy, it is highly unlikely that such a limit will hold up in law or clinical practice. ${ }^{28}$ As the authors of the Model Act recognized, limiting assisted suicide to patients with terminal illnesses would exclude "patients who are not likely to die from their illnesses within six months but have bodily disorders that cause intractable and unbearable suffering, such as AIDS, advanced emphysema, some forms of cancer, amyotrophic lateral sclerosis, multiple sclerosis, and 
many other debilitating conditions." ${ }^{29}$ Because these patients often have years of suffering ahead, their claims for PAS may appear more, not less, deserving of societal support. Indeed, many of the prominent cases of assisted suicide that have captured the public's attention have involved such patients, including many of the individuals whom Dr. Jack Kevorkian has helped to die. ${ }^{30}$

Proponents of legalizing assisted suicide for patients with six months or less to live ignore the fact that efforts to impose such limits on the right to refuse life-sustaining treatment were quickly (and correctly) rejected as arbitrary and unfair intrusions on patients' rights. For example, in Bouvia v. Superior Court, ${ }^{31}$ the California Court of Appeals authorized the removal of a feeding tube from a young woman afflicted with severe cerebral palsy, who had years of life ahead of her, rejecting efforts to limit the right to refuse treatment to patients who are terminally ill. As the Bouvia court observed, "if [the] right to choose may not be exercised because there remains to [the patient], in the opinion of a court, a physician or some committee, a certain arbitrary number of years, months, or days, [the] right will have lost its value and meaning." The New York Court of Appeals has also rejected terminal illness as a constitutional benchmark, ${ }^{32}$ and the justices' varying opinions in Cruzan-a case involving a patient who was not terminally ill-suggest that the U.S. Supreme Court would do the same if it were confronted with the question. ${ }^{33}$ If terminal illness is not an appropriate prerequisite for the refusal of life-sustaining treatment, how can it be a requirement for assisted suicide, particularly if the Second Circuit is correct that distinctions between the refusal of treatment and assisted suicide are arbitrary and discriminatory as a matter of constitutional law? ?4 $^{34}$

Most of the guidelines for PAS that reject terminal illness as an absolute prerequisite stress that assisted suicide should be limited to patients with an incurable physical disease that causes intolerable suffering. For example, the Quill Guidelines provide that the patient must have a condition that is incurable "and associated with severe, unrelenting suffering"; 35 the Miller Guidelines similarly require "unremitting suffering." ${ }^{36}$ As the New York State Task Force on Life and the Law has pointed out, however, "as long as the policies hinge on notions of pain or suffering they are uncontainable; neither pain nor suffering can be gauged objectively or subjected to the kind of judgments needed to fashion coherent public policy." ${ }^{37}$ The authors of the Model Act acknowledge the subjectivity of suffering, concluding that "no objective standard should be imposed on everyone." ${ }^{38}$ But requiring the patient to establish subjective suffering is meaningless; every patient seeking assisted suicide will of course report that life is unbearable, and physicians will have no basis on which to question this judgment, assuming the patient is mentally capacitated.

The second major slippery slope problem raised by most of the proposed guidelines relates to the distinction between a physician's prescription of lethal medication and the physician's direct administration of lethal drugs. This distinction was crucial to the success of the Oregon referendum, and is a central element of the plaintiffs' strategy in the pending constitutional litigation. The authors of the Model Act also decided to approve PAS but not voluntary euthanasia, reasoning that "there would be greater acceptance of the model statute by the public, legislators, and physicians if it were limited to physician-assisted suicide, partly because of the public perception of voluntariness and partly because of the strong ethical objections of some physicians and others to euthanasia." ${ }^{39}$

As the Miller Guidelines recognize, however, allowing physicians to prescribe lethal drugs but not to administer them directly to patients discriminates against patients who want to commit suicide but are too sick to swallow or hold down a pill. These patients may in fact be suffering more than their able-bodied counterparts. They may also feel that asking a trusted physician, family member, or home care attendant to administer lethal medications is ethically indistinguishable from committing suicide by self-administering those medications. ${ }^{40}$

Perhaps the most troubling, and least apparent, slippery slope problem raised by the proposed guidelines relates to their uniform insistence on a contemporaneous request for physician-assisted death by a patient with decision-making capacity. Although this limit may initially appear logically and ethically sound, it is indefensible. Many people who request assisted suicide express a desire to live as long as they are functioning; it is only when they can no longer interact, or when illness or medication causes them to cease to recognize their surroundings, that they would want to end their lives..$^{41}$ If PAS is limited to patients with capacity, patients may end up seeking this option long before they are ready, for fear that if they wait the option will no longer be available. Rather than promoting autonomy, limiting PAS to the mentally competent would therefore create a perverse incentive toward premature suicide, an outcome fundamentally inconsistent with the goal of giving patients control over the timing, manner, and circumstances of their death.

Limiting physician-assisted death to patients with mental capacity would also be inconsistent with developments in law and bioethics over the past twenty years. Beginning with the New Jersey Supreme Court's decision in In re Quinlan, ${ }^{42}$ the law has recognized the importance of respecting patients' wishes and best interests even after they lose decision-making capacity. To protect the individual's right to refuse unwanted life-sustaining treatment after a loss of capacity, the law has created mechanisms like living wills, health care proxies, and surrogate decision making, all of which rely on a good faith assessment of the incapacitated patient's wishes and best interests by health care 
professionals, family members, and close friends. If PAS is legalized, patients without capacity may soon be seen as appropriate candidates for these practices, particularly patients who are permanently unconscious or severely demented. Requests for lethal drugs by family members or others close to the patient are likely to seem compelling for patients who have expressed a desire for PAS as part of an advance directive, or for patients who have given a relative or friend explicit decision-making authority over treatment decisions by signing a health care proxy. Indeed, a footnote in Judge Stephen Reinhardt's opinion for the Ninth Circuit directly opens the door to such practices, by suggesting - contrary to existing law ${ }^{43}$ - that "a decision of a duly appointed surrogate decision maker is for all legal purposes the decision of the patient himself." 44 This means that, even if the law is never changed to legalize euthanasia for the incapacitated, surrogate decision makers could authorize the provision of lethal drugs to incapacitated patients simply by consenting to assisted suicide on the patient's behalf.

\section{Physicians' ability to determine when standards are satisfied}

A second set of concerns about the proposed guidelines for PAS relates not to the instability of the criteria themselves, but to the difficulty of determining when the criteria have been met, even if they remain stable over time. The first of these concerns involves the determination of decision-making capacity. Even if physicians faithfully seek to limit PAS to mentally competent patients who make a contemporaneous request, it is unrealistic to think that most physicians will be successful in this effort, particularly given the high correlation between requests for suicide assistance and clinical depression, an often incapacitating mental illness that physicians are notoriously bad at diagnosing. ${ }^{45}$ This problem is particularly pronounced among patients who are terminally ill, whose physical symptoms of depression may be masked by symptoms of the underlying disease. ${ }^{46}$ Clinicians will also face the difficult challenge of distinguishing between a request that is "distorted by clinical depression" and a request "from a patient suffering from clinical depression [whose] judgment is not distorted." ${ }^{\prime 7}$ It is doubtful that this line will be drawn consistently from one case to the next.

The Model Act attempts to deal with this problem by requiring a mental health consultation in every case, but few of the pending state proposals have adopted this approach. Because " $[\mathrm{t}] \mathrm{he}$ 'suspicion' skills for mental illness among non-psychiatric physicians are so poor, ${ }^{48}$ many cases of depression-induced requests for PAS will inevitably be missed. ${ }^{49}$ Even if psychiatric consultations were required in all cases, it is unlikely that these consultations would do more than screen out the obviously psychotic, given the brevity of the encounter, the patient's efforts to appear rational, and the likelihood that the patient will be referred to a mental health professional who is sympathetic to the patient's desire for PAS. Moreover, as with ordinary decisions about medical treatment, the relevance of "[v]ariable capacity, limited capacity, fluctuating capacity, diminished capacity, and even depression and some forms of mental illness" will be "left to the discretionary judgment of the treating physicians" or other mental health professionals, ${ }^{50}$ which will no doubt be influenced by the physician's own views on the "reasonableness" of the patient's desire to die.

Physicians are also likely to have trouble complying with a second element of the proposed guidelines-the obligation to explore all alternatives and to use assisted suicide as a last resort. All of the guidelines refer to hospice, pain relief, and palliative care, but in many areas of the country these services are simply not available to patients who need them. ${ }^{51}$ Many patients, moreover, cannot or will not pay for these alternatives. If assisted suicide is legalized, will the state ensure that palliative care is available to everyone who needs it, regardless of cost? As a matter of constitutional law, states would be under no obligation to do this; although " $[\mathrm{m}]$ ost Americans believe there should be a 'right to health care,' ... what they have is a right to refuse health care." 52 As such, states would be free to legalize PAS without offering any alternatives for patients to explore.

Even if palliative care services exist in the patient's community and the patient can afford them, legalizing assisted suicide would not ensure that the patient receives those services, or that the services are provided early enough in the patient's illness to make a difference. ${ }^{53}$ As the New York State Task Force on Life and the Law observed, "Numerous barriers contribute to the pervasive inadequacy of pain relief and palliative care in current clinical practice, including a lack of professional knowledge and training, unjustified fears about physical and psychological dependence, poor pain assessment, pharmacy practices, and the reluctance of patients and their families to seek pain relief." ${ }^{4}$ Given the widespread inadequacy of our system of palliative care, it is unrealistic to think that physicians will grant requests for suicide assistance only after all available options to relieve the patient's pain and suffering have been thoroughly explored.

Indeed, if assisted suicide is legalized, it would be impossible to limit the option to patients who have tried other alternatives, for the simple reason that patients cannot be forced to accept any medical treatment they do not want. "[T] he law is, and has always been, that competent adults have the right to refuse any treatment for any reason." 55 Although physicians could be encouraged to offer alternatives to suicidal patients, the law could not require patients to try any of these alternatives as a condition of suicide assistance. In fact, such requirements would probably be 
struck down as unconstitutional, because they would force patients who want lethal medications to waive their constitutionally protected liberty interest in being free of unwanted physical intrusions. ${ }^{56}$ Yet, if physicians help patients commit suicide before any alternatives to relieve pain and suffering have even been attempted, can it really be said that assisted suicide is being used only as a last resort?

PAS guidelines also unrealistically assume that physicians will be able to tell when patients are requesting assisted suicide as a result of pressure, coercion, a sense of obligation, or an unwillingness to challenge what physicians and family members have come to believe is the right choice. It may sometimes be possible to detect explicit coercion by persons with a financial interest in the patient's death (the only risk of legalization that Judge Reinhardt characterized as a "serious concern" ${ }^{57}$ ), but the more subtle coercion that arises from long-standing interpersonal relations will be almost impossible to detect, let alone overcome. ${ }^{58}$ The coercive nature of PAS is most likely to be felt by individuals who are marginalized and vulnerable, such as elderly women who feel obligated to commit suicide to avoid burdening their families, ${ }^{59}$ or disabled individuals who feel that their lives are not valued. ${ }^{60}$ Rather than enhancing autonomy and freedom of choice, legalizing PAS may make these patients feel obligated to justify their desire to continue living, an unfair burden on vulnerable individuals that undermines the possibility for a meaningful exercise of free choice. ${ }^{61}$

Physicians themselves are also likely to influence patients' decisions about assisted suicide, no matter how hard they try to remain objective. It is no secret that patients typically do what their doctors recommend; even when the doctor presents a range of options, some patients will simply choose the option they believe the physician prefers. ${ }^{62}$ Moreover, studies have shown that physicians' own biases and stereotypes affect their decisions to offer lifesustaining or palliative therapies to seriously ill patients. ${ }^{63}$ These biases will affect how physicians present the option of assisted suicide as well.

Some of the guidelines attempt to prevent the physician from influencing the patient's decision by providing that the physician may not raise the issue of assisted suicide unless the patient initiates the discussion. This limitation, however, is meaningless, because a patient can simply ask the physician for all available options, and the physician would then be ethically obligated to provide a complete response. ${ }^{64}$ Moreover, physicians have become accustomed to initiating discussions about forgoing life-sustaining treatment in cases thought to be appropriate, and in the privacy of the consultation room it is unlikely that a gag order will inhibit them from being equally forthcoming about the option of assisted suicide. Other proposed guidelines attempt to limit PAS to "meaningful doctor-patient relationships," ${ }^{65}$ but this requirement is ambiguous and unenforceable, nor does it appear in any of the pending state legislative proposals. Indeed, under many of the proposals, there is nothing to prevent two physicians from establishing a "physician-assisted suicide 'mill'," where the issue of assisted suicide is the first and last matter that the doctor and patient ever discuss. ${ }^{66}$

Finally, the guidelines fail to offer a realistic mechanism for monitoring the practice, a problem that may be insurmountable given the private setting in which decisions about assisted suicide are likely to take place. Although oversight of decisions about life-sustaining treatment has not proved to be a problem, those decisions generally occur in hospitals or long-term care facilities, enabling extensive monitoring, data collection, and review. PAS, by contrast, will most likely take place in the home, with prior discussion in the physician's office. In such private settings, no system of oversight is likely to be effective. Moreover, mechanisms to ensure accountability and review are inherently inconsistent with the proposals' overall emphasis on privacy and autonomy, and might ultimately be challenged as unjustifiable intrusions on the exercise of the patient's rights. ${ }^{67}$

The Miller Guidelines go farther than any in setting up a system of prospective and retrospective review, but none of the pending state legislative proposals has adopted this approach. Instead, most assume that physicians themselves will report cases of assisted suicide, which may facilitate retrospective monitoring but could not ensure adequate prospective review. Moreover, it is unlikely that insulation from legal liability will be a sufficient motivation for many physicians to report cases of PAS to the public authorities, particularly those physicians who are now willing to assist in suicides in violation of existing law.

\section{Conclusions}

How the law should respond when suffering patients request assisted suicide is a question worthy of serious public debate. In considering this question, however, it is crucial to define the scope of the issues correctly. Contrary to what many advocates for legalization claim, the critical question is not whether helping a patient commit suicide can ever be an appropriate act. Rather, the important question, and the one less often debated, is whether a system can be set up that can distinguish the exceptional cases, where assisted suicide may be ethically defensible, from the many other cases where PAS could also be prescribed. It would be wrong to assume that regulation to solve this problem will be possible, particularly when so many logi$\mathrm{cal}$ and ethical inconsistencies exist in all of the guidelines proposed to date.

The debate about assisted suicide has generated tremendous interest in the care and treatment of dying patients, yet legalization is far from the most critical need of 
seriously ill patients today. What fuels the growing interest in assisted suicide is widespread fear of loss of control, isolation, depletion of family resources, and unrelieved pain and suffering toward the end of life. We ought to focus our attention and advocacy on addressing these problems directly, by ensuring access to necessary and appropriate medical and social services and promoting health care decision making respectful of patients' and families' values. Legalizing assisted suicide will not solve the problems of dying patients, and it may well create many more. The development of guidelines, while necessary if PAS is legalized, will not ensure that the practice is limited to a narrowly defined class of ethically defensible cases.

\section{References}

1. "A.M.A. Keeps Its Policy Against Aiding Suicide," New York Times, June 26, 1996, at C9.

2. A.L. Back et al., "Physician-Assisted Suicide and Euthanasia in Washington State: Patient Requests and Physician Responses," JAMA, 275 (1996): 919-25; J.G. Bachman et al., "Attitudes of Michigan Physicians and the Public Toward Legalizing Physician-Assisted Suicide and Voluntary Euthanasia," N. Engl. J. Med., 334 (1996): 303-09; and M.A. Lee et al., "Legalizing Assisted Suicide-Views of Physicians in Oregon," N. Engl. J. Med., 334 (1996): 310-15.

3. Oregon Death with Dignity Act, Or. Rev. Stat. $\mathbb{\$} \$ 127.000$ et seq. (1995).

4. Even opponents of legalizing PAS have questioned the legal basis for the injunction. For example, A.M. Capron, "Constitutionalizing Death," Hastings Center Report, 25, no. 6 (1995): 23-24; and C.H. Coleman and T.E. Miller, "Stemming the Tide: Assisted Suicide and the Constitution," Journal of Law, Medicine \& Ethics, 23 (1995): 389-97.

5. D. Callahan and M. White, "The Legalization of Physician-Assisted Suicide: Creating a Regulatory Potemkin Village," University of Richmond Law Review, 30 (1996): 1-83.

6. Compassion in Dying v. State of Washington, 79 F.3d 790 (9th Cir. 1996) (en banc); and Quill v. Vacco, 80 F.3d 716 (2d Cir. 1996).

7. For example, F.G. Miller et al., "Regulating PhysicianAssisted Death,” N. Engl.J. Med., 331 (1994): at 119 (PAS should be treated as a "nonstandard medical practice reserved for extraordinary circumstances"); T.E. Quill, C.K. Cassel, and D.E. Meier, "Care of the Hopelessly Ill: Proposed Clinical Criteria for Physician-Assisted Suicide," N. Engl. J. Med., 327 (1992): at 1381 (assisted suicide should be used "only after all other alternatives have been exhausted and failed"); and H. Brody, "Assisted Death-A Compassionate Response to a Medical Failure," N. Engl. J. Med., 327 (1992): at 1385 (assisted suicide should only be performed for those "few patients" who "will face a bad death despite all medical efforts").

8. 79 F.3d at 820 .

9. Quill et al., supra note 7.

10. Miller et al., supra note 7.

11. For example, D.T. Watts and T. Howell, "Assisted Suicide Is Not Euthanasia," Journal of the American Geriatrics Society, 40 (1992): 1043.

12. Miller et al., supra note 7 , at 120.

13. Or. Rev. Stat. $\int \mathbb{S} 127.00$ et seq. (1995).

14. C.H. Baron et al., "A Model Statute to Authorize and
Regulate Physician-Assisted Suicide," Harvard Journal on Legislation, 33 (1996): 1-34.

15. Dr. Jack Kevorkian, for example, has proclaimed that his current activities are simply "the first concrete step in a longrange plan" to "develop a rational policy of planned death for the entire civilized world." M. Betzold, "Kevorkian Asks Supreme Court to Affirm Right to Aid in Dying," Dallas Morning News, Mar. 12, 1995, at 4A.

16. E.J. Emanuel and E. Daniels, "Oregon's Physician-Assisted Suicide Law," Archives of Internal Medicine, 156 (1996): 825-29.

17. The New York State Task Force on Life and the Law, When Death Is Sought: Assisted Suicide and Euthanasia in the Medical Context (New York: New York State Task Force on Life and the Law, 1994).

18. Id. at xv.

19. $I d$. at xiii.

20. Callahan and White, supra note 5, at 2-3.

21. Id. (quoting Miller et al., supra note 7).

22. G.J. Annas, "The Promised End: Constitutional Aspects of Physician-Prescribed Suicide," N. Engl. J. Med., 335 (1996): at 684 ("[T]he ability to objectively distinguish between good and bad suicides is critical.").

23. Id.; Coleman and Miller, supra note 4; see also S.A. Law, "Physician-Assisted Death: An Essay on Constitutional Rights and Remedies," Maryland Law Review, 55 (1996): 292 342 (arguing that the practice can be limited, but acknowledging that, "[i]f there were no other, more precisely tailored, means of avoiding abuse," the argument for an absolute prohibition "would have force").

24. S. Bok, "The Leading Edge of the Wedge," Hastings Center Report, 1, no. 3 (1971): 9-11.

25. Y. Kamisar, "Against Assisted Suicide-Even a Very Limited Form," University of Detroit Mercy Law Review, 72 (1995): 735-69 (suggesting that "liberal" supporters of PAS "defended the Nazis' right to march to Skokie largely because they feared that denying them First Amendment protection might start us down a slippery slope").

26. R.A. Sedler, "Are Absolute Bans on Assisted Suicide Constitutional? I Say No," University of Detroit Mercy Law Review, 72 (1995): 725-33.

27. R.A. Sedler, "The Constitution and Hastening Inevitable Death," Hastings Center Report, 23, no. 5 (1993): 20-25 ("In no meaningful sense of the term can a choice to hasten one's own inevitable death by the use of physician-prescribed medications be labeled a 'suicide."'); see also Compassion in Dying, 79 F.3d at 824 ("[W]e are doubtful that deaths resulting from terminally ill patients taking medication prescribed by their doctors should be classified as 'suicide."').

28. Even if it does, it is worth noting that terminal illness is a far less objective concept than it initially appears. Callahan and White, supra note 5, at 45 ("One searches the literature in vain for consistency regarding the meaning of terminal condition or terminal disease.").

29. Baron et al., supra note 14 .

30. W.J. Smith, "Depressed? Don't Go See Dr. Kevorkian," New York Times, Sept. 16, 1995, at 19 (noting that at least half of the individuals whom Dr. Kevorkian helped to die were not terminally ill).

31. Bouvia v. Superior Court, 225 Cal. Rptr. 297 (Cal. Ct. App. 1986).

32. Fosmire v. Nicoleau, 75 N.Y.2d 218 (1990).

33. Annas, supra note 22, at 686 (Cruzan stands for the proposition "that an adult need not be terminally ill to refuse treatment”). 
34. Quill, 80 F.3d at 729; Y. Kamisar, "The Reasons So Many People Support Physician-Assisted Suicide-And Why These Reasons Are Not Convincing," Issues in Law \& Medicine, 12 (1996): at 130 ("If the Second Circuit's equal protection analysis is sound, how can we prevent persons suffering serious but not terminal illnesses from enlisting the aid of another to die by suicide when patients with the same non-terminal illnesses who are on life support systems may hasten their deaths by directing the removal of such systems?") (emphasis in original).

35. Quill et al., supra note 7, at 1381.

36. Miller et al., supra note 7, at 120.

37. New York State Task Force on Life and the Law, supra note 17 , at 132 .

38. Baron et al., supra note 14 , at 11 .

39. Id. at 10 .

40. As Erich Lowey has argued, "Killing others who are terminally ill at their own request when they are incapacitated and unable to implement their own wishes is a form of assisted suicide in circumstances where nonassisted suicide is no longer possible." E.H. Lowey, "Healing and Killing, Harming and Not Harming: Physician Participation in Euthanasia and Capital Punishment,"Journal of Clinical Ethics, 3 (1992): 29-34.

41. L. Shavelson, A Chosen Death: The Dying Confront Assisted Suicide (New York: Simon \& Schuster, 1995).

42. In re Quinlan, 70 N.J. 10 (1976).

43. Most laws authorizing surrogate decision making for incapacitated patients limit the scope of the decision maker's authority, some quite extensively. See generally, Choice in Dying, Right-to-Die Law Digest, Dec. (1995): passim.

44. Compassion in Dying, 79 F.3d at 832 n.120.

45. L. Eisenberg, "Treating Depression and Anxiety in Primary Care: Closing the Gap Between Knowledge and Practice," N. Engl. J. Med., 326 (1992): 1080-84 ("The evidence is clear that the diagnostic skills of many generalists are inadequate to the task.").

46. M.J. Massie and J.C. Holland, "The Cancer Patient with Pain: Psychiatric Complications and Their Management," Journal of Pain and Symptom Management, 7 (1992): 99-109.

47. Baron et al., supra note 14 , at 18 .

48. Emanuel and Daniels, supra note 16, at 828.

49. In a recent survey of Oregon physicians, one-third stated that they were "not confident they could recognize depression in a patient asking for a lethal dose of medication." Lee et al., supra note 2 , at 313 .

50. Callahan and White, supra note 5, at 37.

51. J. Rhymes, "Hospice Care in America," JAMA, 264 (1990): 369-72.

52. G.J. Annas, “The 'Right to Die' in America: Sloganeering from Quinlan and Cruzan to Quill and Kevorkian," Duquesne Law Review, 34 (1996): at 877.

53. N.A. Christakis and J.J. Escarce, "Survival of Medicare Patients After Enrollment in Hospice Programs," N. Engl. J. Med., 335 (1996): 172-78 (concluding that most Medicare patients who enter hospice do so late in the course of their illnesses, even though they are eligible for admission much earlier).

54. New York State Task Force on Life and the Law, supra note 17 , at xi.

55. Annas, supra note 52, at 877.

56. L.H. Tribe, American Constitutional Law (New York: Foundation Press, 2nd ed., 1988): \11-5, at 781 ("Indepen- dently unconstitutional conditions-those that make enjoyment of a benefit contingent on sacrifice of an independent constitutional right—are invalid.”).

57. Compassion in Dying, 79 F.3d at 825-26.

58. Callahan and White, supra note 5 , at 7 ("While strongwilled sick and suffering people may be able to resist patent and gross coercion, they may have far more difficulty contending with well-meaning manipulation and gentle, discreet suggestion.”).

59. S.M. Wolf, "Gender, Feminism, and Death: PhysicianAssisted Suicide and Euthanasia," in S.M. Wolf, ed., Feminism and Bioethics: Beyond Reproduction (New York: Oxford University Press, 1996): at 291 ("The history and persistence of family patterns in this country in which women are expected to adopt self-sacrificing behavior for the sake of the family may pave the way too for the patient's request for death."); and S. Gutmann, "Death and the Maiden," New Republic, June 24, 1996, 20-23 (asking whether "a certain type of woman-depressive, self-effacing, near the end of a life largely spent serving others-is particularly vulnerable to the 'rational,' 'heroic' solution" of assisted suicide).

60. P.S. Miller, "The Impact of Assisted Suicide on Persons with Disabilities-Is It a Right Without Freedom?," Issues in Law \& Medicine, 9 (1993): at 61 ("Because persons with disabilities are subject to prejudice that devalues their very right to exist, their decisions to commit suicide are not necessarily informed or voluntary.").

61. J.D. Velleman, "Against the Right to Die," Journal of Medicine \& Philosophy, 17 (1992): 665-81 ("The most important way in which the option of euthanasia may harm patients, I think, is that it will deny them the possibility of staying alive by default.").

62. New York State Task Force on Life and the Law, supra note 17 , at 122 ("[P]atients generally do what their doctors recommend.").

63. N.J. Farber et al., "Cardiopulmonary Resuscitation (CPR): Patient Factors and Decision Making," Archives of Internal Medicine, 144 (1984): 2229-32; R.M. Wachter et al., "Decisions About Resuscitation: Inequities Among Patients with Different Diseases but Similar Prognoses," Annals of Internal Medicine, 111 (1989): 525-32; and American Medical Association, Council on Ethical and Judicial Affairs, "Black-White Disparities in Health Care," JAMA, 263 (1990): 2344-46.

64. Gag rules have frequently been criticized in other contexts as inconsistent with the physician's obligation to be complete and truthful. For example, G.J. Annas, "Restricting Doctor-Patient Conversations in Federally Funded Clinics," N. Engl. J. Med., 325 (1991): 362-64 ("In the doctor-patient context, a half-truth is the same as a lie, and it violates both medical ethics and the doctrine of informed consent.").

65. Quill et al., supra note 7, at 1382.

66. Emanuel and Daniels, supra note 16, at 827 ("[A]s written, the Act could permit Jack Kevorkian or the Hemlock Society to establish physician-assisted suicide 'mills' with just two physicians serving terminally ill patients from all over the United States.”).

67. D.M. Gianelli, "Study: Patients in Pain Don't Want Assisted Suicide," American Medical News, July 29, 1996, at 6-7 (noting that Derek Humphry, author of the suicide manual Final Exit, "had doubts about whether a mental health [consultation] requirement could pass constitutional muster"). 